translation of an ancient prescription for curing the tooth-ache. The sufferer was ordered to mix some beer with oil and with another unknown ingredient, and, having rubbed it on his tooth, he recited the following words three times:- "When Anu had created the heavens, the heavens created the earth, the earth created the rivers, the rivers created the canals, the canals created the marshes, the marshes created the Worm, which came and wept before Shamash and cried out before Ea, saying:- "What wilt thou give me for my food? What wilt thou give me to eat?' To this the Sun-God replied :-' I will give thee dry bones and scented... wood.' To this the Worm made answer:- 'Of what use are dry bones and scented ... wood to me? Let me drink between the teeth and let me be at the gums, that I may drink the blood of the teeth and sap the strength of the gums, then shall I be master of the bolt of the door.'" When the patient had said the above, he was ordered to address the Worm and say, "May Ea smite thee with

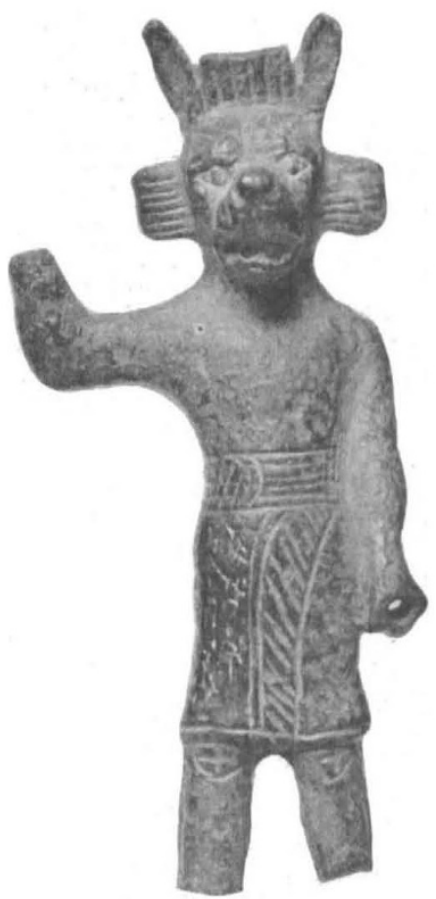

FIG. 1.-Bronze animal-headed figure of one of the Babylonian Powers of Evil. From "The Devils and Evil Spirits of Babylonia."

the strength of his fist, O Worm!"

We can only hope that these potent words relieved the sufferer.

The bulk of Mr. Thompson's present volume is, of course, occupied with the transliterations and literal translations of the documents of which he treats; but, as these are manifestly intended for the expert in cuneiform only, we may briefly note the summaries of their contents, which appear in the preface. The texts which refer to words of power show that they possessed much in common with a similar class of document found in Egypt and elsewhere. The Sumerian magician having found out the name of the devil which caused the sickness he was called upon to cure, proceeded to deal with it by means of sympathetic magic. He employed ceremonies of various kinds, in which magical figures, loaves of bread, pieces of hair, water, a virgin kid, \&c., played prominent parts. Sicknesses could be transferred to the dead bodies of kids and pigs, and devils could be made to disappear into masses of water collected in pots, whereupon the vessels themselves would break. In Sumer and Accad knotted cords were much used for purposes of witchcraft, and knotted locks of hair were held to be allpowerful. The section which treats of the ban and taboo is especially suggestive, and we hope that $\mathrm{Mr}$. Thompson will say more on these subjects when he has collected a larger number of examples. Finally, he directs attention to the existence of the word "Kuppuru," which is the equivalent in meaning to the Mosaic idea of "atonement," and the texts printed in the volume before us show conclusively that the acts which formed the atonement removed the taboo which man had incurred. The Sumerian ceremonies of atonement were certainly developed out of sympathetic magic, and the examples of atonement given in the Bible show that the ceremonies mentioned were, in more than one case, closely connected with primitive Hebrew magic. Those who are interested in the study of magic in all its forms will find Mr. Thompson's book of considerable interest and importance.

\section{SPEECH CURVES.}

$A \mathrm{~N}$ interesting lecture ${ }^{1}$ was recently delivered in the psychological institute of the University of Berlin by Prof. Scripture, of the University of Yale, whose investigations in phonetics are well known. Prof. Scripture's method is that first employed by Fleeming Jenkin and Ewing, and afterwards developed by Hermann, the writer and others, namely, to record on a moving surface, either by photography or by a direct system of levers, the curves imprinted by speech on the cylinder of a phonograph or on the disc of a gramophone. Dr. Scripture has recently improved the mechanism of his apparatus so as to obtain an amplification of the curves, about three times in the horizontal and three hundred times in the vertical direction, while the speed of the movement of his gramophone plate was reduced 126,300 times that at which it rotates during the acoustical reproduction of the sound. His curves have been submitted to analysis, and it shows the energy with which the research is being prosecuted when he is able to state that in America he has twenty persons engaged in this special bit of work.

In the discussion of his results, Prof. Scripture, in the first instance, refers to some remarks by Prof. Sievers, of Leipzig, on what may be called the " melody" of vowels and words. Prof. Sievers says that each line and verse of a poem has its own melody, and that this will be determined by the psychological condition of the individual at the time of its vocal expression. An author, too, while writing a poem, say one of a dramatic character, may give a certain " melody" to the expressions of one individual. Goethe, for example, causes Faust to drop his voice at the close of a sentence, while the voice of Mephistopheles rises and falls in a variable manner. Sievers also points out, as a curious fact, that when Goethe completed the poem, many years after he wrote the earlier portions, he had forgotten these melodic effects, and the later portions have not the same melodic characteristics. Prof. Scripture supports Prof. Sievers's view. This melodic character will thus affect the quality of a vowel sound.

Prof. Scripture holds that the movement of the vocal cords does not produce a sinuous curve, and herein he agrees with Marage, of Paris. By the movements of the cords a number of sudden and more or less violent shocks are given to the air, and each shock is communicated to the air in the resonators. In this way 1 "Über das Studium der Sprach Kurven." By E. W. Scripture. Annalen der Naturphilosophie. (Leipzig: Veit and Co.).

$$
\text { No. I } 837 \text {, VOL. } 7 \text { I } 7
$$


we can interpret the groups of marks made on the wax cylinder of the phonograph. Each group corresponds to a " shock" from the cords, and the smaller curves making up the group are due to the movements of the air in the resonators. Prof. Scripture is not satisfied with the theory of Helmholtz that the resonators develop overtones in a harmonic series, nor with that of Hermann, who asserts that the resonance tones need not necessarily be harmonic. He states that he cannot interpret his tracings by the rigid application of either of these theories, and he lays stress on the fact that the walls of the resonating cavities above the cords are not rigid like the resonators of musical instruments, but are soft, as if the wall were fluid. Such a resonator, he says, will give its own tone in response to all tones. We confess that here we are not able fully to comprehend the author's meaning.

Prof. Scripture endeavours also to establish a close relationship between the form of the vibration of the cords and the action of the resonators. According to him, the form of the vibration of the cord may be altered by changes in the action of the muscular fibres that tighten the cord, so as to produce a tone of a given

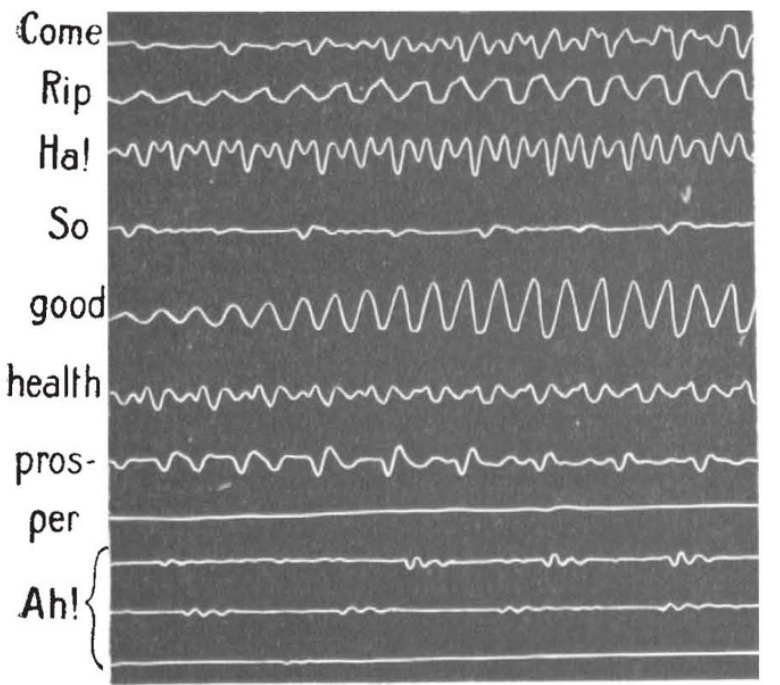

Frg. x.-Curves of Rip van Winkle's Toast, spoken by the American actor, Joseph Jefferson.

pitch. Assuming that each muscle fibre has a separate nerve fibre (which is highly improbable), one can see that the tension of the cords, even when adapted to the production of a tone of a given pitch, might be so modified as to give out a tone-wave of a special form, and that thus an almost infinite variety of qualities of tone (tone-colours) might be produced. The special quality of tone would thus in the first instance depend on the psychical condition of the individual at the moment. In the next place, according to Prof. Scripture, the "water-wall" resonators, as he calls them, will develop their own tones, independently of the cord-tones, and thus, again, by a summation of these tones, the quality of the vowel-tone may be almost infinitely varied. In this way there is a physiological association between the movements of the cords and the action of the resonators.

Prof. Scripture also notes that each vowel has its own harmony, depending on the resonators, and that if it is sounded for even a short time its " melody" may change. This is why it is that when we examine the waves corresponding to a vowel as transcribed from the gramophone they are often seen to change in character as we approach the end of the series of waves. The writer can corroborate this view from his observations by his own method of recording directly the vibrations of a phonograph recorder on a rapidly moving glass plate.

Prof. Scripture also points out a fact that was soon apparent to all observers in experimental phonetics, namely, that in the records of the phonograph or gramophone there are neither syllables nor intermediate glides, but a succession of waves, infinitely diverse in form, corresponding to the tones of the voice or the sounds of any musical instrument. The sound of a single vowel may be in a groove a metre long on the wax cylinder of the phonograph, and in the bottom of this groove there may be thousands of little groups of waves. The writer possesses records of songs that if drawn out would be Ioo metres in length. Finally, Prof. Scripture lays emphasis on the effect of varying intensity as influencing quality. Apart from the theory of vowel-tones advanced by the author, this interesting lecture owes its value to the way in which Prof. Scripture approaches the problem from the physiological and psychological side. The mode of production of vowel-tones is in this sense not entirely a physical problem. We are dealing with living cords moved by living muscles, and with curiously shaped resonators having living walls.

\section{JoHn G. McKendrick.}

\section{GEOLOGY OF SPITI. ${ }^{1}$}

THERE are spots, insignificant in themselves, which have a world-wide celebrity among those interested in certain pursuits or investigations. Such is Gheel to the alienist, Shide to the seismologist, or Bayreuth to the musician, and such, too, is Spiti, a barren and sparsely inhabited valley in the centre of the Himalayas, which has long been known to geologists for its extensive series of richly fossiliferous rocks. A district like this could not long escape the notice of the Geological Survey of India, and one of the earliest volumes of its memoirs is that by Dr. F. Stoliczka and F. R. Mallet. Published in 1864, this remained the standard, and practically the only, description of the geology of Spiti until the publication, in I89x, of Mr. C. L. Griesbach's memoir, in which, while adopting his predecessors' mapping in the main, he introduced great modifications in the sequence. Neither of these descriptions, however, is entitled to rank as more than a reconnaissance, but now we have the results of what may fairly be described as a survey of this region, and, in an interesting and clearly expressed memoir, Mr. Hayden has gone far towards clearing up the points which were in dispute. In all cases where he has found himself at variance with his predecessors' conclusions he has produced good evidence, and it is in one way satisfactory that he is generally in agreement with the one who can no longer defend his views.

The Spiti valley contains representatives of every series from Cretaceous to Silurian, and a Cambrian age is inferred for a series of sedimentary, but unfossiliferous, beds underlying the latter. In all these Mr. Hayden not only collected from known, but also discovered several previously unknown, fossil-horizons, among the most interesting of which we may mention that of the land plants of Culm age. In the Silurian he has restored Stoliczka's correlation and fully supported it by fossil evidence; on the other hand he has confirmed Mr. Griesbach's discovery of Lower Triassic beds, and his conclusion that there is, in Spiti, a continuous conformable sequence from Permian to Upper Trias, and in this connection has rendered ample I "The Genlogv of Spiti, with Parts of Bashahr and Rupshu." By H. H. Hayden. (Memoirs of the Geological Survey of India, vol. xxxvi., part i.) Hayden. (Memoirs of the Geological Survey of India, vol. xxxvi., part i.)
Pp. vitiz2; illustra:ed. (Calcutta : Government Printing Office, r $; 04$. 